\title{
Vascularized Fibular Graft Reconstructing Large Bone Defects after Extended Curettage of Osteolytic Lesions in Lower Extremities
}

\author{
Gao MX' ${ }^{1}$ Li H ${ }^{2}$, Nie DJ ${ }^{2}$, Liu C ${ }^{1}$, Xie WQ ${ }^{2}$, Chang $\mathrm{YF}^{2}$, Luo WY ${ }^{1^{*}}$ \\ ${ }^{1}$ The Third Department of Orthopedics Surgery, Gansu Province Hospital, Lanzhou, Gansu, China, 730000 \\ ${ }^{2}$ Department of Orthopedic Surgery, Lanzhou General Hospital of PLA, Lanzhou, Gansu, China, 730050 \\ *Corresponding Author: Luo WY, The third Department of Orthopedic Surgery, Gansu Province Hospital, NO. \\ 204 Donggangxi Road, Chengguan District, Lanzhou, Gansu Province, China, Email: xenyuanluo1966@163.com
}

\begin{abstract}
Background: Benign lytic lesions of bone encompass a group of neoplasm or disorders of human skeleton. Planning a treatment protocol for patients with osteolyic lesions of lower extremity involves many concerns of different risks. Especially, the reconstruction of large bony defects following surgical resection of the lesions presents a challenge for the operating surgeon.
\end{abstract}

Materials and Methods: Twenty-three cases of benign bone tumors or tumor-like lesions in the lower extremities treated between April 2013 to March 2016 were retrospectively analyzed. Lesion was scooped out with extended curettage technique and the tumor wall was treated by zinc chloride. Vascularized fibular grafting with or without plate fixation were performed to reconstruct bone defect. The patients were followed up and assessed with the MSTS score (Musculoskeletal Tumor Society score) and radiological images.

Results: The mean follow-up term is for 43.1 months, ranging from 24 to 77 months. One patient of giant cell tumor developed recurrence at 12-month follow-up, who finally died from lung metastasis. The other 22 patients showed no sign of recurrence. Overall, there was no evidence of avascular necrosis of fibular graft in any case. The average time of bony union between vascularized fibular graft and the receipt site was 4.3 months (rang, 2-7 months). The mean MSTS scores of pre-operation and post-operation were (80.87 \pm 23.49$) \%$ and (93.19 $\pm 17.39) \%$, respectively, which showed that the functional outcomes of affected limbs were averagely restored to excellent level at the final follow-up.

Conclusions: The outcomes showed that vascularized fibular grafting following extended curettage and zinc chloride treating is a reliable and effective surgical option in the management of benign bone tumors or tumorlike lesions in the lower extremities.

Keywords: Benign bone tumors, tumor-like lesions, curettage, zinc chloride, vascularized fibular graft

\section{INTRODUCTION}

Benign tumors and tumor-like lesions of bone encompass a broad category of miscellaneous conditions, which tend to form osteolytic destruction of bone [1].

Both ends of femur and the proximal end of tibia have been described to be most commonly affected by these lesions [1-4]. Because osteolytic lesions weaken the bones, pathologic fractures, one of serious consequences, are likely to occur to the involved bones $[1,5]$. It has been reported that the risk of pathological fracture rises with lesion's size if the peritrochanteric region of femur is affected by osteolytic lesions. Specifically, the cortex of tumor site is destroyed more than half in diameter or $22 \mathrm{~mm}$ in length $[2,5]$. Thus, choosing an effective treatment for these lesions is a demanding job for the orthopaedic surgeon, who has to take all the involved factors into account, including removal of the lesion, reconstruction of the bone defect, prevention of the lesion from recurrence, avoidance of complications and restoration of limb function.

The main purpose of this paper is to evaluate the outcomes of 23 cases with active benign tumors or 
tumor-like lesions in lower extremities managed by extended curettage and vascularized fibular graft with or without plate fixation.

\section{Materials ANd Methods}

All patients signed informed consent for publication of their data before being included in this retrospective study, which was approved by the local ethical committee and performed in accordance with the ethical standards. Between April 2013 and March 2016, ten female and 13 male patients were treated and followed up for active benign tumor or tumor-like lesion in the bones of lower extremities. The average age of the patients at the time of surgery was 27.8 years, ranging from seven to 73 years. Tumors or lesions occurred on left side were in 11 patients and right side in 12 patients. The most common complaint was blunt pain and restriction of joint movements among all the patients. These four patients could not walk normally upon admission. The tumor site of 14 cases was in proximal femur, three in femoral diaphysis, one in distal femur, two in proximal tibia and three in the diaphysis of tibia. Two patients already had pathological fracture on plain radiography on admission. Another two was confirmed having occult fracture of cortex by CT scanning (Table $1)$.

All patients, without exception, received a package of examinations, including plain X-ray, computed tomography (CT) scanning and magnetic resonance imaging (MRI) of the suspected bone and adjacent joints. In four patients of giant cell tumor, emission computed tomography (ECT) was used to study the activity of the tumor and CT of the chest was also done to check lung metastasis.

With the aid of c-arm fluoroscopy, pre-operative needle biopsy was done to gain the histological diagnosis (Table 1) and to help making proper surgical procedures. There were ten patients having benign tumors, including four giant cell tumors (GCT), two osteoid osteomas, two desmoplastic fibromas, one enchondroma and one chondromyxoid fibroma (CMF). The other 13 patients had tumor-like lesions, including six fibrous dysplasias (FD), three aneurysmal bone cysts (ABC), three simple bone cysts (SBC), and one brown tumor of hyperparathyroidism.

Operations were performed under general anesthetic. Two teams of surgeons collaborated efficiently, team one for removal of the lesion, team two for harvesting vascularized fibula. Depending on the difference of tumor site, appropriate incision was designed to expose and remove the lesion fully. At least one artery and its two accompanying veins were dissected, which would be reunited with the vessels of the fibula. For example, given that the tumor grows in the proximal femur, hip anterior approach (SmithPetersen incision) [6] would be applied. Meanwhile, the ascending branch of the lateral femoral circumflex artery and its two veins typically run in here, so these vessels would be used for transplanting the vascularized fibula here by microvascular technique.

After finishing the exposure of tumor site, usually before any further step, the cortex just over the lesion was pricked and a piece of tumor tissue sample was taken out for rapid frozen section to rule out any possibility of malignancy once again. Only if the diagnosis of frozen sectioning matches that of the pre-operative needle biopsy, suggesting benign tumor or tumorlike lesion, the pricked hole would be expanded to a cortical window as large as the lesion. Extended curettage of the lesion was implemented via the window with the procedures as described by Kundu et al [7]. The bulk of the tumor was scooped out and kept for routine pathological examination. There often was a sclerotic margin on the inner side of the cavity. It was burred with a high-speed bur until bony surface with punctate visible bleeding. Next, the $50 \%$ zinc chloride was used as an adjuvant to "burn" the tumor cavity chemically [8]. After that, the cavity was further treated with hydrogen peroxide, distilled water and twice of saline in sequence. Nooks and corners were carefully washed to avoid leaving residual tumor cells in the cavity. The surgeons of team one were required to change gloves, gowns, draping and instruments and got ready for the reconstruction of bone defect with the vascularized fibula.

As long as it was confirmed by rapid frozen section that the lesion was benign, the surgeons in team two would start to make a longitudinal incision over the lateral aspect of the fibula [9]. Superficial dissection was performed in the interval between the peroneus longus muscle anteriorly and the soleus posteriorly. The diaphysis of the fibula was then circumferentially exposed, leaving a 5-mm layer of soft tissue as "muscular sleeve", with carefully preserving the periosteal blood supply to fibula. No matter pedicled or free vascularized fibula would be harvested (Fig. 1a, b), the peroneal artery and 
veins were identified along the posterior aspect of the fibula and separated till their original junction with posterior tibial vessels.

Following the treatment of the lesion, the fibula was transplanted to the host site. Mostly, the fibula was cut into segments and folded to fit the bony cavity (Fig. 2) [10,11]. Under microscope, one artery and two veins of the free fibular were anastomosed to the dissected vessels in the host site with 10-0 microsurgical stitches, reinstituting both arterial inflow and venous outflow to the fibular graft. The punctate bleeding from the surface of "muscular sleeve" was considered as a sign of satisfactory anastomosis, which was present in all our cases. Mostly, a locking plate was used to fix the affected bone. Minimally invasive percutaneous plating technique and image intensification was used. The plate was placed like a bridge over the tumor-weakened site, while precautions was taken to avoid the screws interfering the blood supply of the transplanted fibula (Fig. 3, 4, 5). Closure in layers was done with negative pressure drain.
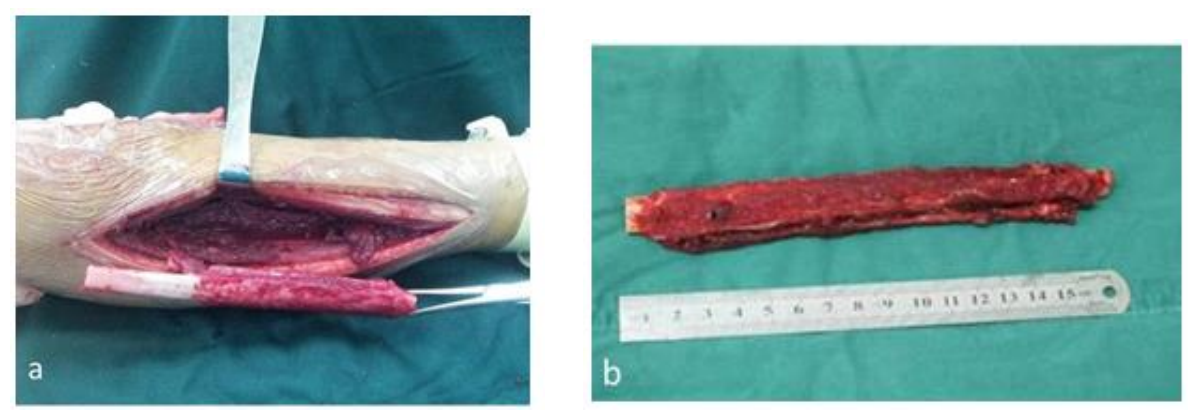

Fig1. Fibular graft harvested with peroneal vessels and soft-tissue "muscle sleeve". The proximal end of peroneal vessels is intact for pedicled transplant (a). The both ends of peroneal vessels have been cut for free vascularized graft (b).
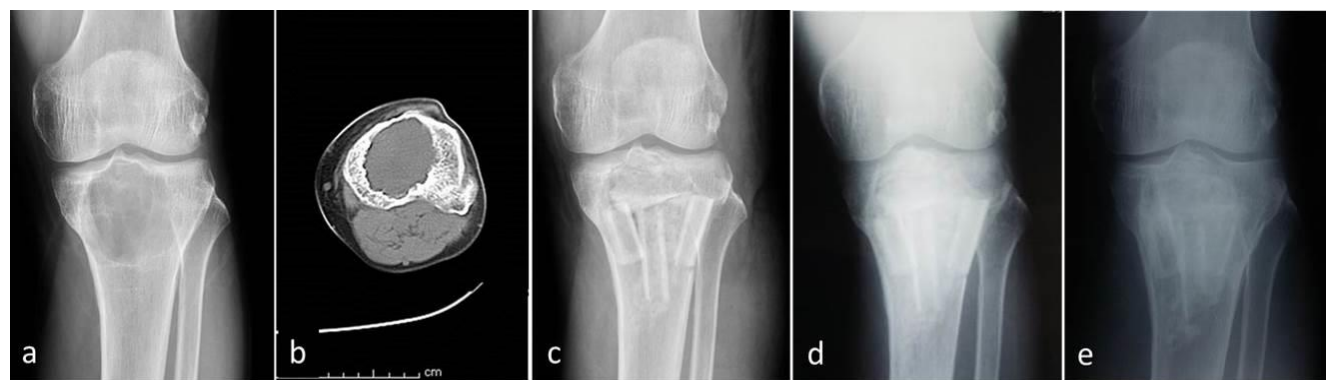

Fig2. Case 1. A 41-year-old male with giant cell tumor of the left proximal tumor. Preoperative X-ray (a) and CT scanning (b) show that the osteolytic lesion destructed more than $50 \%$ bone in the transverse section. $c$, immediately postoperative X-ray. $\boldsymbol{d}, X$-ray at 6-month follow-up. $\boldsymbol{e}, X$-ray at final follow-up (71months) showing healing of the lesion and bone fusion between the vascularized fibular graft and the recipient bony cavity.
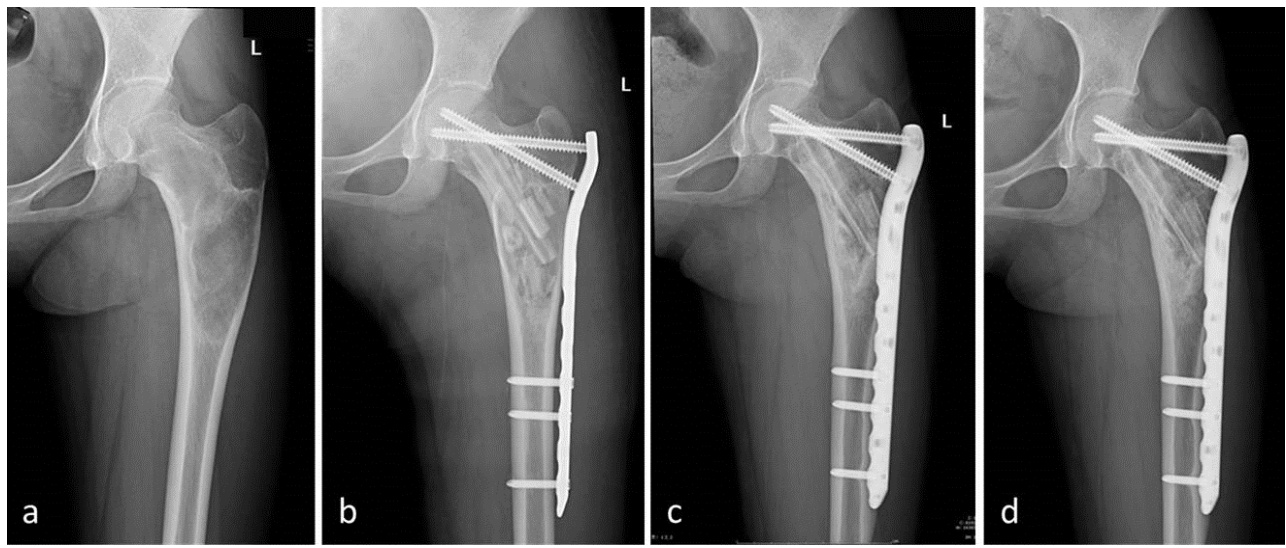

Fig3. Case 2. A 27-year-old female with fibrous dysplasia of the left proximal femur. Preoperative X-ray (a) shows the "ground glass"appearance of the clearly defined, fibro-osseous femoral neck lesion. $\boldsymbol{b}$, X-ray immediately after the surgery. $\boldsymbol{c}, X$-ray at 6-month follow-up shows no evidence of recurrence. $d, X$-ray at final follow-up (25months) showing consolidation and reconstruction of the femoral neck. 

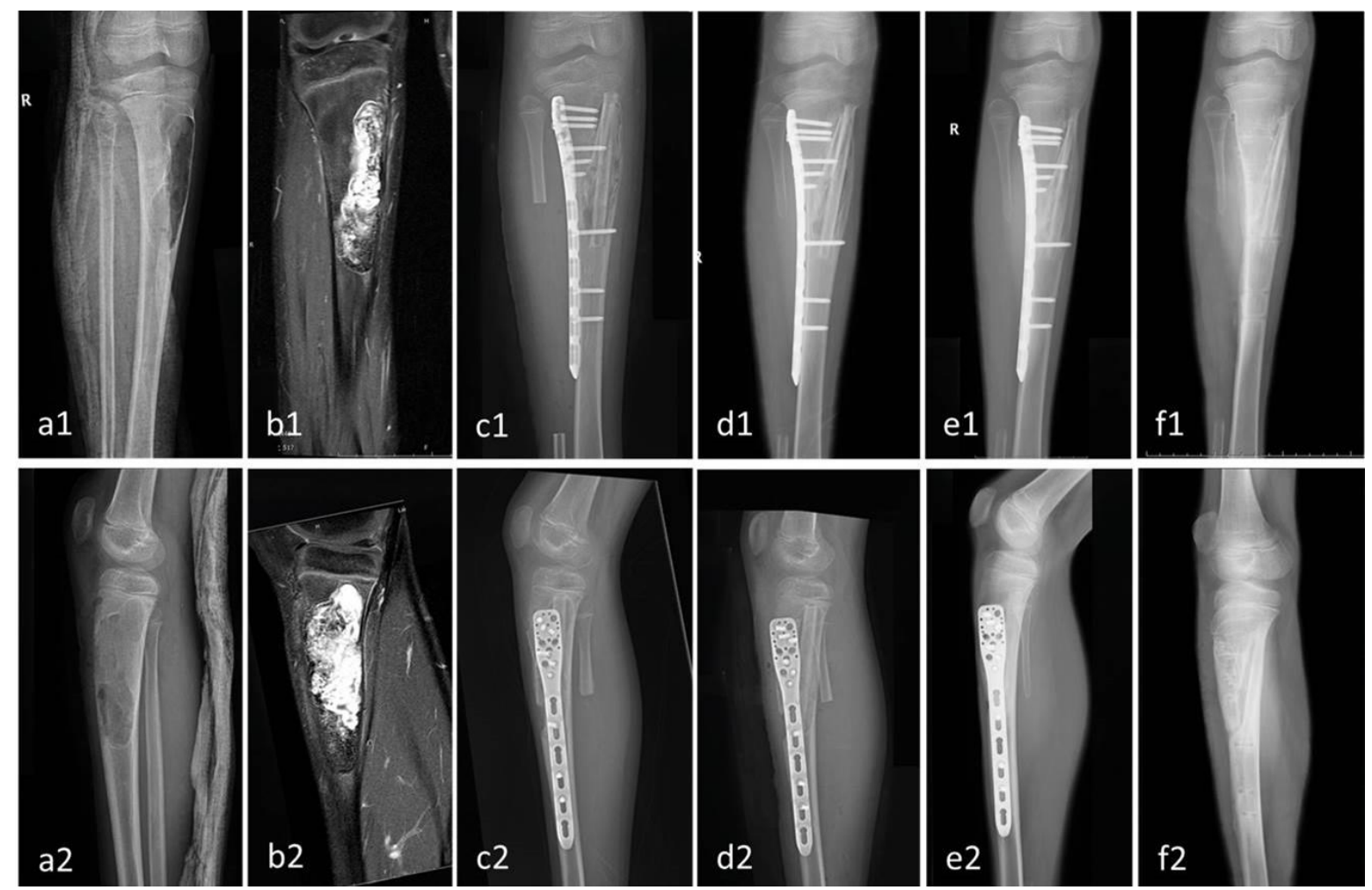

Fig4. Case 8. A 9-year-old male with chondromyxoid fibroma. X-ray (a) and MRI (b) radiolucent lesion with sclerotic contours in the diaphysis of the right tibial. $\mathrm{c} X$-ray immediately after the surgery shows pedicled vascularized fibular graft was transplanted for rebuilding ipsilateral tibial defect. X-ray at 3-month (d) and 9month (e) follow-up show no progression of the valgus deformity of the knee and no recurrence of the lesion. $X$ ray at final follow-up (20 months) (f) shows the internal fixation was removed and bone healing was excellent.
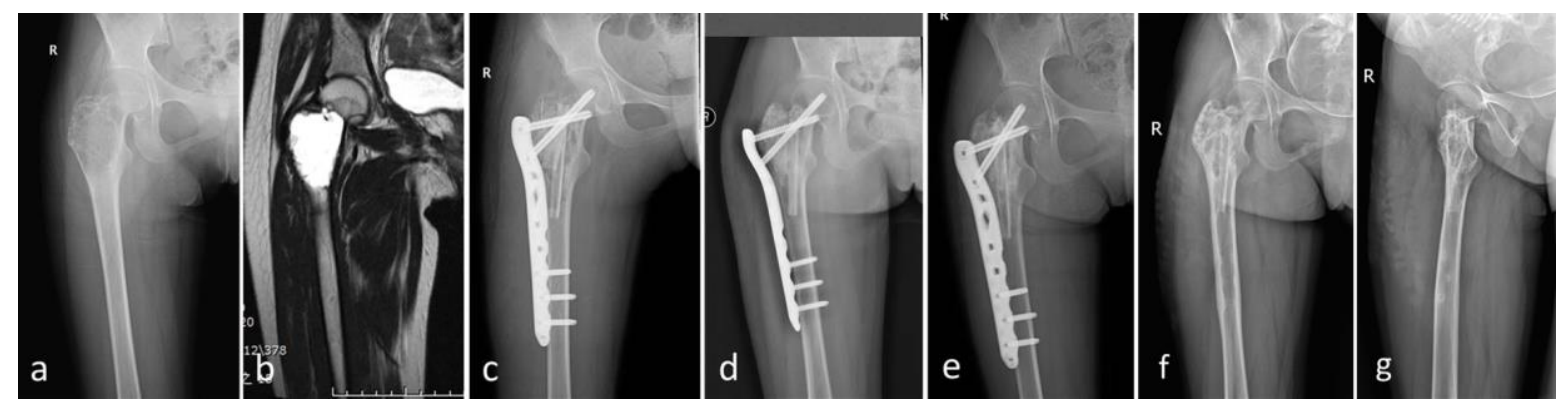

Fig5. Case 13. A 16-year-old female with aneurysmal bone cyst (ABC). X-ray (a) and MRI (b) show radiolucent and osteolytic lesion in the trochanteric area of right femur. Due to post-operative deep hemorrhage, she developed subcutaneous liquefactive necrosis at the incision, which healed after the second surgery. c, X-ray immediately after the surgery. X-ray at 3-month (d) and 12-month (e) follow-up show no recurrence of the lesion. $X$-ray at final follow-up (42 months) $(\boldsymbol{f}, \mathrm{g})$ shows the internal fixation was removed and bone healing was excellent.

During the induction of anaesthesia a bolus dose of prophylactic antibiotics were usually given intravenously to ensure adequate tissue concentrations at the beginning of surgery. Because the surgeries most frequently lasted longer than four hours, another dose of antibiotic was utilized to maintain a persistent tissue concentration. Intravenous dextran and subcutaneous heparin were administrated for 3-5 days to decrease vascular thrombosis of the fibula graft. [12, 13]
The drain system was usually removed within 48 hours. The suture was removed at 14 days. Early postoperative exercises started in the recovery room shortly after the operation to keep normal joint motion and muscle strength. The weightbearing and daily activities were gradually encouraged, which were thought very important for their full recovery.

Patients were followed up monthly within the first six months after surgery and then every three months for the following years. The preoperative 
and postoperative functional conditions were evaluated by the MSTS score (Musculoskeletal Tumour Society Score), which is originally described by Enneking et al in 1987 [14]. It is calculated on the basis of a standardized physical examination by the assessor. This incorporates in six clinical examinations. It's criteria differs slightly between the upper and lower limb. Three of them are pertinent to patients as a whole such as pain, functional activities, and emotional acceptance. The other three are use of external supports, walking ability, and gait, which are specific for the lower limb. Each item is scaled from 0 to 5 , with a maximum score of 30 . The values of all items were added, and the functional score was presented as a percentage of the maximum possible score. The higher the score is, the better the function is, vice versa.

At follow-up points, X-ray, sometimes CT, was done to figure out any signs of recurrence, pathological fractures or osteonecrosis. The changes in the lesion border, adjacent joint, as well as the status of internal fixation were observed (Fig. 2, 3, 4). Table 1 shows the clinical details of all the patients, including gender, age, diagnosis, tumor location, size of tumor, existing pathological fracture or not, pedicled or free fibula being transplanted, with internal fixation or without, bony healing time and the MSTS scores [14].
There were two patients, who were preoperatively diagnosed as aneurysmal bone cyst, had problems in incision healing. One developed subcutaneous liquefactive necrosis. The other had post-operative deep hemorrhage, which was thought as a result of bleeding from the fibula graft. Both were treated by debridement without the removal of the bone graft. The wounds successfully healed without infection two weeks after the second surgery. The incisions of all other cases healed very well as expected.

There was a child, who was diagnosed chondromyxoid fibroma (CMF) in his right tibia. Though a mild valgus deformity of the ipsilateral knee was found in a child case with, no progression of the valgus deformity showed up until 45 months follow-up, comparing with his pre-operative radiographs (Fig 4).

On 12-month follow-up, a 38-year-old female developed tumor recurrence, which originally was diagnosed as giant cell tumor (GCT) of right proximal femur (Fig. 6). Although she underwent extensive resection of the proximal femur, reconstruction with customized prosthesis (Fig. $6 \mathrm{~g}$ ) and post-operative adjuvant radiotherapy, the patient eventually died from lung metastases and its complications 7 months after the revision surgery.

\section{ReSUlts}
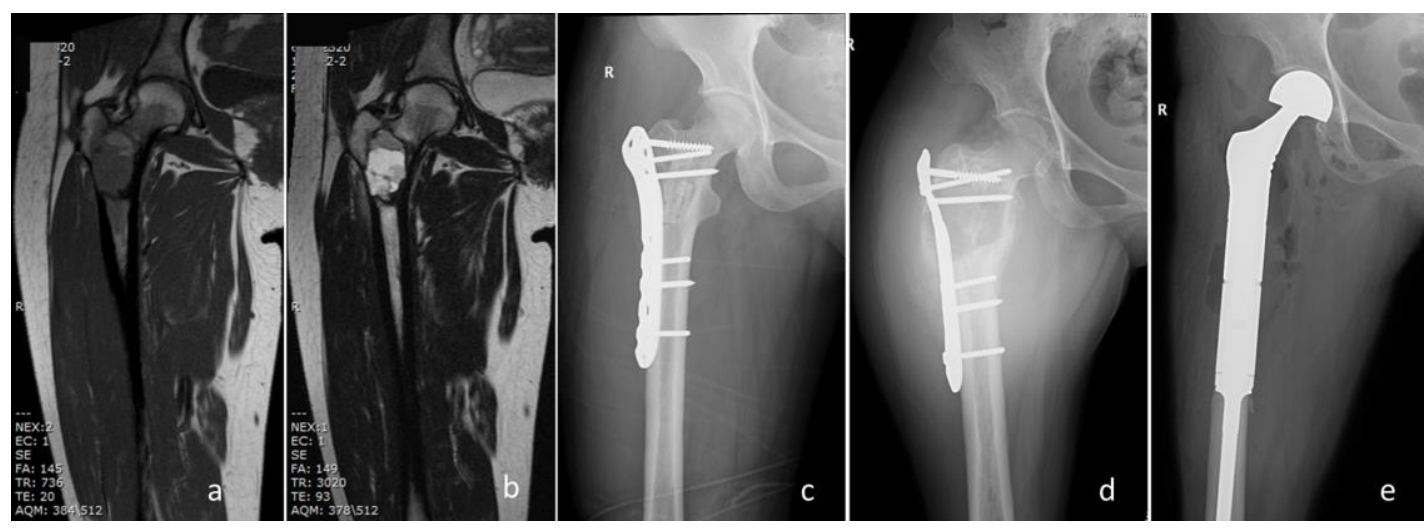

Fig6. Case 18. A 38-year-old female originally was diagnosed giant cell tumor (GCT) of right proximal femur (a, b). c, X-ray immediately after the surgery. On 12-month follow-up, she developed tumor recurrence (d). She underwent extensive resection of the proximal femur, reconstruction with customized prosthesis (e).

The mean length that all patients were followed up was 43.1 months, ranging from 24 to 77 months. Except for the above case of death, all the other 22 patients showed disease free at the final follow-up. Among them, there was no evidence of 1) local recurrence or distant metastases, 2) loosening or fracture of the fixed plates, 3) pathologic fractures, 4) avascular necrosis or other complications of the fibular graft, 5) stiffness of adjacent joints. Bony union was achieved in all these 22 patients, which was approved by walking without pain and gradual disappearance of the gap between fibula and the bone in host site, with trabeculae growing across it (Fig 2, 3, 4, 5). The average time of bony union showed on radiography was 4.3 months, ranging from 2 to 7 months. The preoperative and postoperative MSTS scores were $80.04 \% \pm$ $24.09 \%$ (6.67\%-100.00\%) and $93.19 \% \pm 17.39 \%$ (16.67\%-100.00\%), respectively. 
Table1. Clinical details of patients

\begin{tabular}{|c|c|c|c|c|c|c|c|c|c|c|c|c|c|c|c|c|c|c|c|c|c|}
\hline $\begin{array}{l}\dot{0} \\
0 \\
0 \\
0\end{array}$ & ma & $\stackrel{\dot{a}}{8}$ & $\overrightarrow{\dot{\infty}}$ & $\begin{array}{l}0 \\
\infty\end{array}$ & \begin{tabular}{l}
$\hat{6}$ \\
\multirow{2}{*}{}
\end{tabular} & $\underset{\infty}{m}$ & $\underset{\infty}{m}$ & $\stackrel{\circ}{8}$ & $\stackrel{\circ}{\circ}$ & $\hat{\sigma}$ & $\begin{array}{l}\hat{6} \\
0 \\
0\end{array}$ & $\begin{array}{l}\stackrel{0}{\dot{0}} \\
\end{array}$ & $\stackrel{m}{\sim}$ & $\begin{array}{l}0 \\
\dot{\infty}\end{array}$ & $\tilde{\sigma}$ & \begin{tabular}{c|c}
$m$ \\
$\stackrel{n}{r}$ & $\dot{m}$ \\
\end{tabular} & $\stackrel{m}{\tilde{p}}$ & $\hat{\infty}_{\infty}$ & $\begin{array}{cc}m & 0 \\
\alpha & 0 \\
\alpha & 0 \\
\end{array}$ & $\begin{array}{l}\ddot{\dot{a}} \\
\dot{8}\end{array}$ & $\begin{array}{l}0 \\
\dot{\infty} \\
\end{array}$ \\
\hline 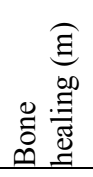 & $m$ & $\nabla$ & + & $\sigma$ & $n$ & $n$ & 0 & $m$ & $\theta$ & $n$ & 6 & $\sim$ & $n$ & $n$ & $\theta$ & $r$ in & & in & $m \sim$ & $\theta$ & $m$ \\
\hline 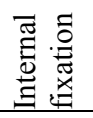 & & + & + & & & + & & + & + & + & + & 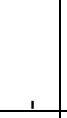 & + & + & + & $+\quad+$ & + & + & $+\quad+$ & + & + \\
\hline 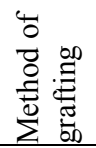 & 总 & 苋 & 总 & $\begin{array}{l}\vec{z} \\
\frac{0}{0} \\
\bar{J} \\
0 \\
\tilde{D}\end{array}$ & 总 & 总 & 总 & \begin{tabular}{|c|}
$\vec{z}$ \\
$\frac{0}{0}$ \\
$i \vec{z}$ \\
0 \\
0 \\
\end{tabular} & 总 & 总 & 总 & \begin{tabular}{|l|}
$\vec{z}$ \\
$\frac{0}{0}$ \\
$: \vec{z}$ \\
0 \\
$\tilde{e}$
\end{tabular} & 总 & 总 & 总 & 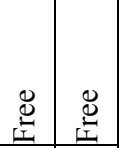 & 总 & 总 & 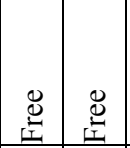 & $\begin{array}{l}\vec{z} \\
\frac{0}{0} \\
: \vec{z} \\
0 \\
0 \\
\end{array}$ & 苋 \\
\hline 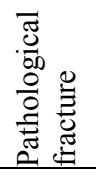 & $z$ & Z & $z$ & $z$ & z & $z$ & $z$ & z & $z$ & $z$ & $\lambda$ & z & $\lambda$ & z & Z & $z$ & $z$ & $z$ & $z \quad z$ & $z$ & $\lambda$ \\
\hline 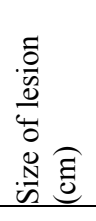 & 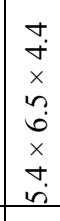 & $\begin{array}{l}0 \\
\dot{+} \\
x \\
n \\
i \\
i \\
x \\
m \\
n \\
n\end{array}$ & $\begin{array}{l}\infty \\
i \\
x \\
0 \\
0 \\
\infty \\
x \\
n \\
n \\
m\end{array}$ & $\begin{array}{c}n \\
n \\
x \\
x \\
n \\
i n \\
x \\
-5 \\
0\end{array}$ & 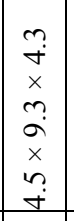 & 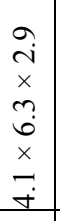 & $\begin{array}{l}0 \\
\dot{+} \\
x \\
n \\
\mathfrak{b} \\
x \\
\infty \\
\infty \\
\dot{+} \\
\end{array}$ & $\begin{array}{l}\hat{i} \\
x \\
\dot{a} \\
\dot{a} \\
x \\
n \\
\vec{i}\end{array}$ & $\begin{array}{l}0 \\
\dot{m} \\
x \\
0 \\
\dot{b} \\
x \\
\infty \\
\infty \\
\dot{j}\end{array}$ & 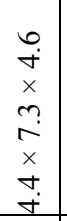 & $\begin{array}{c}m \\
\dot{p} \\
x \\
n \\
m \\
\dot{n} \\
x \\
n \\
\dot{p} \\
\end{array}$ & $\begin{array}{l}n \\
i \\
x \\
x \\
0 \\
x \\
x \\
n \\
i \\
i\end{array}$ & $\begin{array}{l}\hat{i} \\
x \\
n \\
n \\
n \\
x \\
\tilde{n} \\
m \\
\dot{n}\end{array}$ & $\begin{array}{l}0 \\
\dot{b} \\
x \\
0 \\
0 \\
b \\
x \\
r \\
\infty \\
\infty\end{array}$ & 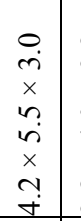 & 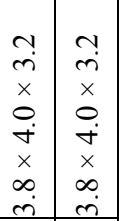 & $\begin{array}{l}\dot{0} \\
\dot{m} \\
x \\
0 \\
\dot{n} \\
x \\
m \\
m \\
\dot{m}\end{array}$ & $\begin{array}{l}0 \\
\dot{m} \\
x \\
0 \\
\dot{n} \\
\dot{x} \\
0 \\
\dot{+}\end{array}$ & \begin{tabular}{c|c}
$n$ & $n$ \\
$i$ & 0 \\
$x$ & $x$ \\
$n$ & 0 \\
$n$ & 0 \\
$\dot{x}$ & $\dot{0}$ \\
$x$ & $x$ \\
$\infty$ & 0 \\
$i$ & $i$
\end{tabular} & $\begin{array}{l}m \\
\vec{i} \\
x \\
\infty \\
\infty \\
\dot{n} \\
x \\
\vec{i} \\
\vec{i}\end{array}$ & $\begin{array}{l}2 \\
i \\
x \\
x \\
0 \\
\dot{x} \\
x \\
n \\
n \\
\end{array}$ \\
\hline 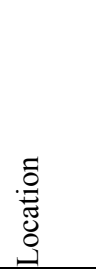 & 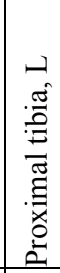 & 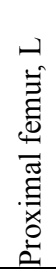 & 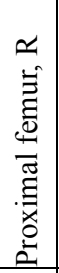 & 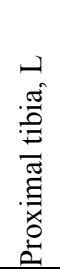 & 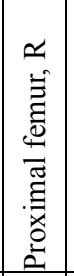 & 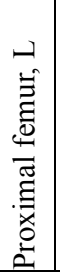 & 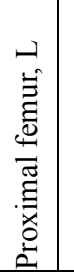 & 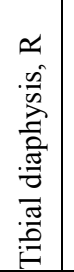 & 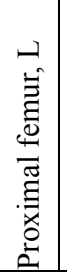 & 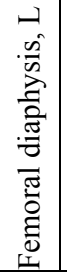 & 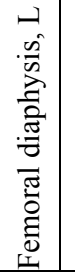 & 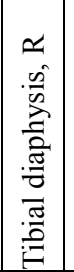 & 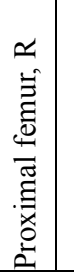 & 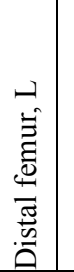 & 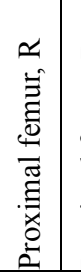 & 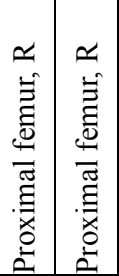 & 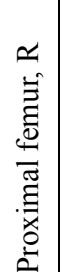 & 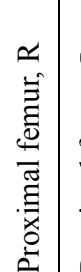 & 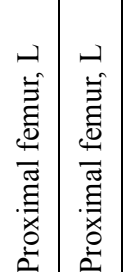 & 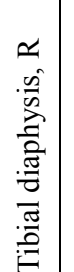 & 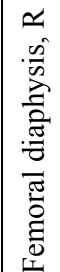 \\
\hline 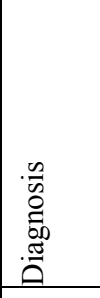 & U & 全 & 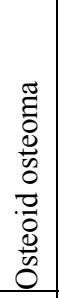 & 电 & 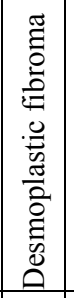 & 王 & 苞 & $\sum_{U}^{L}$ & 空 & 品 & 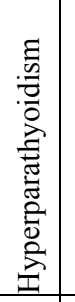 & 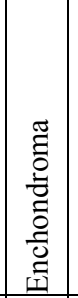 & 总 & E & 全 & 呈总 & t⿹ & 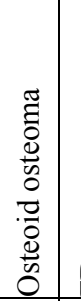 & \begin{tabular}{l|l}
0 & 0 \\
0 & 0
\end{tabular} \mid & 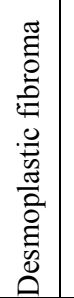 & $\begin{array}{l}u \\
\mathscr{N} \\
\tilde{N}\end{array}$ \\
\hline $\begin{array}{l}8 \\
0 \\
\end{array}$ & $F$ & $\bar{\imath}$ & $\stackrel{i}{n}$ & 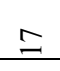 & $\bar{m}$ & $\underset{\sim}{2}$ & त) & $a$ & $\pi$ & $\hat{\imath}$ & 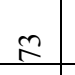 & r & $\stackrel{0}{\simeq}$ & f & ते & \begin{tabular}{l|l|} 
\\
\end{tabular} & $\stackrel{\infty}{n}$ & $m$ & $\cong \cong$ & $\stackrel{0}{n}$ & $=$ \\
\hline 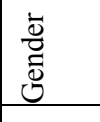 & $\Sigma$ & L & $\Sigma$ & $\omega$ & $\Sigma$ & $\Sigma$ & $\Sigma$ & $\Sigma$ & 山 & $\Sigma$ & 工 & L & 工 & $\Sigma$ & $\omega$ & $\Sigma \Psi$ & 山 & $\Sigma$ & $\Sigma \Sigma$ & $\Sigma$ & $\Sigma$ \\
\hline $\begin{array}{l}\mathscr{D} \\
\tilde{\omega} \\
\tilde{u}\end{array}$ & - & & $m$ & $\theta$ & $\ln$ & 6 & $r$ & $\infty$ & $a$ & 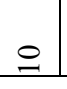 & $=$ & $\simeq$ & $\underline{9}$ & \pm & $\stackrel{n}{\sim}$ & $\stackrel{2}{\simeq}=$ & $\stackrel{\infty}{=}$ & 2 & $\stackrel{\vec{\imath}}{ }$ & ה & $a$ \\
\hline
\end{tabular}




\section{DISCUSSION}

Diversities in cellular origin or tissue source make differential diagnosis of tumors and tumorlike lesions of bones quite complicated and ambiguous. It is not rare that uncertain diagnoses, even misdiagnoses, appear in the reports of pathological examination $[15,16]$. The main treatments used for benign tumors and tumor-like lesions of bone are surgery. The operation varies depending on the type and site of the tumor. In some cases, tumors themselves are benign, but they are more destructive because the affected bones are adjacent to joints. It is challenging to design the surgical procedures, which involves how to completely remove the tumor and how to reconstruct the bone that's been affected or removed. It is even more difficult to avoid operative complications if the aim of treatment is to restore limb function without any loss $[1,2,4]$.

Curettage is one of the most common treatment options for benign lytic bone tumors and tumorlike lesions [1-4,17-19]. However, after intralesional curettage of these lesions, highspeed burring, electrocautery, phenol, hydrogen peroxide, liquid nitrogen and absolute alcohol are generally advocated by many surgeons as several adjuvant treatment methods to reduce the rate of local recurrence $[4,8,20,21]$. It was reported that diluted aqueous zinc chloride solution was previously applied as a kind of disinfectant [22]. It also was used as an alternative chemical to cause eschars and scabs of cancer tissue [23]. In our cases, we treated the lesion wall using $50 \%$ aqueous zinc chloride solution to destroy the remaining cells and thus to reduce the risk of local recurrence. This solution, as a chemical, has characteristics of permeability, corrosion, protein denaturation and cytotoxicity [8]. It can infiltrate 1-2 mm cortical bone to effectively kill remnant tumor cells hiding in the lacunae of the tumor bed.

Giant cell tumor (GCT) is known as one of the most common benign bone tumors. It is locally aggressive and sometimes may metastasize to lungs $[19,24,25]$. Rock et al. had reported a sixfold higher risk of lung metastasis in patients who experienced local recurrence of GCT compared with patients with no history of local recurrence [24]. Local recurrence of GCT is considered as a risk factor for lung metastasis in many studies [19].
Some scholars advocate wide resection of GCT affected segment and prosthetic reconstruction to prevent local recurrence in the patients with higher risk. Wide resection of the entire tumor theoretically offers an advantage of lower recurrence risk, but it is usually associated with poor long-term outcome [7,11,19-21,26]. It is reported that local recurrence rate of GCT could be as high as $20 \%$ after intralesional curettage, but curettage has advantages of joint preservation and excellent functions $[21,27]$. The four patients of GCT were relatively young in this study. The tumor lesions were confined in intact cortical walls. No obvious pathological fracture was found on radiography. We used curettage combining with burring and zinc chloride as adjuvant treatments to treat these cases of GCT. Unfortunately, one GCT at Campanacci stage III [28] had local recurrence on 12-month follow-up (Fig. 6).

This 38-year-old female patient finally died from lung metastasis. The other three cases of GCT remained disease-free with satisfactory limb function until the latest follow-up (Fig. 2). However, there were only four cases of GCT involved in this study. The sample size was too small to say whether the surgical treatment we used was good enough to treat GCT without controversy.

Fibrous dysplasia (FD) is a common tumor-like bone disorder, accounting for $5-10 \%$ benign bone lesions, which rarely becomes malignant $[4,29,30]$. Because bone-forming cells fail to mature and produce too much fibrous tissue, the replacement of normal bone may lead to pain, misshapen bones, and pathological fracture, especially when it occurs in the long bones, like proximal femur (Fig. 3). Surgical treatment might not be required in an asymptomatic case of FD. However, surgery is recommended if a fracture occurs or is likely to occur. Surgery may also be indicated to relieve pain or be in an effort to correct the shape of the bone $[4,29,30]$. If a symptomatic lesion of FD continues to grow even in mature bone, it is essential to perform a biopsy and make a confirmed diagnosis [4]. FD can affect one bone or multiple bones, also known being monostotic or polyostotic. Curettage with cancellous bone graft usually produces satisfactory results in treating patients with monostotic lesion. However, it is not easy at all to completely remove out the lesion without residue. The left lesion could replace the implanted cancellous bone quickly and lead treatment to failure. This is especially true for the 
lesion occurring in proximal femur, where the lesion can be very large and grow very actively $[4,31,32]$. There were six cases of FD included in this study, which all located in the proximal femur with no exception. The mean size of lesions was 89.9 cubic centimeters. In these cases, the limited bone harvested from iliac crest was not enough to fill the large bony cavity. The iliac bone graft is not strong enough in proximal femur.

An aneurysmal bone cysts (ABC) are benign tumour-like bone lesions, which are blood-filled, fibrous cysts of uncertain aetiology. The lesion of $\mathrm{ABC}$ can cause pain, swelling and fractures with aggressive and destructive processing in the affected bone [33]. In this study, No recurrence showed in the three patients with $\mathrm{ABC}$, who underwent curettage, high-speed burring and zinc chloride. Well bone healing was observed in all cases up to two years of follow-up (Fig. 5). We believe that treating lesion wall with zinc chloride is a key contributor to this good result.

Benign bone tumors generally are not life threatening, but some of them aggressively replace healthy bone tissue with abnormal tissue. So these tumors can weaken the bones they develop in. There would be a resultant defect after curettage of a bone tumor, which usually needs to be filled up. Materials that can be used in filling usually are divided in four groups: autografts, allografts, xenografts and synthetic biomaterials $[1,4,6-8]$.

Bone cement is one of alternative biomaterials, which has been used for a long time but not biodegradable. It can provide structural support with strong compressive strength that is greater than cancellous bone, but it poorly resists shear and torsion $[1,8]$. Therefore, if bone cement is used to pack the defects in the bones of lower extremities, there would be high risk of occurring fracture through the tumor site, where shearing and torsional stress always act [8,34]. Among these materials, autologous bone graft is considered as gold standard, because it has the best osteoconductive and osteoinductive properties $[1,35,36]$. It contains viable osteogenic cells and bone morphogenetic proteins (BMPs), which are the most vulnerable things to stimulate bone regeneration $[35,36]$.

It also has been reported that the risk of pathological fracture increases with the size of lesion [37,38]. Kundu ZS et al used sartorius pedicled bone grafting to treat 16 patients with benign lytic lesions in the femoral neck and achieved excellent outcome in all patients. [1] In this study, the tumor site of 14 cases was the proximal femur, autologous bone only harvested from iliac crest is often not adequate to fill up the large cavity in the intertrochanteric region of femur. In some cases, the lesion almost destructed the femoral neck so that it was very close to the cartilage of femoral head (Fig. 3). It is convenient to harvest bone graft from the patient's iliac crest under the same anesthetic. However, the iliac bone graft is often not only limited in quantity, but also not strong enough in quality. In other words, the supporting strength of iliac bone sometimes doesn't meet the mechanical requirements of the lower extremity. On the other hand, the iliac bone graft is not vascularized. The process of creeping substitution takes a very long time to be completed. During this process, the activities of the patients have to be confined, from which muscle atrophy, disuse osteoporosis, joint stiffness and other serious complications are likely to result. Since Taylor GI et al [9]. Firstly used vascularized fibular graft to reconstruct a large defect in a tibia in 1975, free vascularized fibular graft has been widely accepted for the reconstruction of long bone defect, especially when the defect is greater than $6 \mathrm{~cm}[10,11]$. Malizos $\mathrm{KN}$ et al. stated that free vascularized fibular graft is also indicated if the blood supply of lesion site is deficient [39]. Enneking WF et al. reported that the bony union rate of nonvascularized bone grafts was very low in a series of cases with over 7-cm bone defects [40]. However, vascularized fibular graft has advantages in reconstruction of important structures, such as intertrochanteric area, femoral neck, etc. because it can not only provide a large volume of bone graft but also strong mechanical support for the host site $[11,39,41,42]$. Vascularized fibular graft lives on its own vessels. So, theoretically, neither avascular necrosis nor creeping substitution is necessary. It takes a shorter time to finish bony union between vascularized fibular graft and host site than the process of creeping substitution. Because vascularized fibular graft has its own blood supply, it has ability to protect bone graft from infection $[12,13,41]$.

It should not be neglected to restore mechanical strength of the bones weakened by tumor after the tumor is completely removed [1,41]. 
Applying internal fixation is a common way to prevent the bone of tumor site from happening postoperative pathologic fracture [42]. Patients can be more confident in performing postoperative exercises to avoid joint adhesion, osteoporosis and muscle atrophy of the affected limb. In our study, we used locking plate in 18 cases. Because the incidence of bone tumor and tumor-like lesions is relatively low, there were only 23 patients of our department could be included in this study. It is hard to have another group of patients as control to compare with these patients who underwent vascularized fibular graft. Second, the mean follow-up of our patients is for about 43 months. The time just goes beyond the term during which most recurrences occur [43-45]. A longer term follow-up of these patients is planned to carry on.

In summary, the initial mid-term results of this series of patients are quite encouraging. Our strategy is comprehensive, but effective in the management for patients with benign bone tumors or tumor-like lesions, in which we applied curettage, zinc chloride, vascularized fibular graft and internal fixation. The surgical technique of vascularizing fibular graft is demanding. It is hard to be proficiently mastered by the surgeons. However, if it is successfully applied in treating the patients with bone tumors or tumor-like lesions, the patients will benefit from reduced recurrence of tumor and rapid restored functions of the involved limb.

\section{REFERENCES}

[1] Kundu ZS, Gogna P, Sangwan SS, Garg R, Kamboj P, Singla R. Benign lytic lesions of the femoral neck: mid-term results of extended curettage and sartorius muscle pedicle bone grafting. Arch Orthop Trauma Surg. 2013; 133:457-462.

[2] George B, Abudu A, Grimer RJ, Carter SR, Tillman RM. The treatment of benign lesions of the proximal femur with non-vascularised autologous fibular strut grafts. J Bone Joint Surg Br. 2008;90:648-651.

[3] Başarir K, Pişkin A, Güçlü B, Yildiz Y, Sağlik Y. Aneurysmal bone cyst recurrence in children: a review of 56 patients. J Pediatr Orthop. 2007;27:938-943.

[4] Kushare IV, Colo D, Bakhshi H, Dormans JP. Fibrous dysplasia of the proximal femur: surgical management options and outcomes. J Child Orthop. 2014;8:505-511.
[5] Sim E, Lang S. Joint salvaging surgery for an extensive giant cell tumor of the proximal femur complicated by a transcervical fracture. Arch Orthop Trauma Surg. 1997;116:431-434.

[6] Smith-Peterse MN. Approach to and exposure of the hip joint for mold arthroplasty. J Bone Joint Surg Am. 1949;31A(1):40-6. PMID: 18122877

[7] Kundu ZS, Gupta V, Sangwan SS, Rana P. Curettage of benign bone tumors and tumor like lesions: A retrospective analysis. Indian J Orthop 2013;47(3):295-301. doi: 10.4103/ 00195413.111507.

[8] Zhen W, Yaotian H, Songjian L, Ge L, Qingliang W.J Bone Joint Surg Br. 2004 Mar;86(2):212-6. Giant-cell tumour of bone. The long-term results of treatment by curettage and bone graft.

[9] Taylor GI, Miller GD, Ham FJ.The free vascularized bone graft. A clinical extension of microvascular techniques. Plast Reconstr Surg. 1975 May;55(5):533-44.

[10] Liang K, Xiang Z, Chen S, Cen S, Zhong G, Yi M, Huang F. Folded free vascularized fibular grafts for the treatment of subtrochanteric fractures complicated with segmental bone defects. J Trauma Acute Care Surg 2012; 72:1404-1410.

[11] Bi ZG, Han XG, Fu CJ, Cao Y, Yang CL. Reconstruction of large limb bone defects with a double-barrel free vascularized fibular graft. Chin Med J (Engl) 2008;121:2424-2428.

[12] Zhen P, Hu YY, Luo ZJ, Liu XY, Lu H, Li XS. One-stage treatment and reconstruction of Gustilo Type III open tibial shaft fractures with a vascularized fibular osteoseptocutaneous flap graft. J Orthop Trauma 2010;24:745-751.

[13] Zhen P, Liu XY, Lu H, Li XS. Fixation and reconstruction of severe tibial shaft fractures with vascularized fibular grafting. Arch Orthop Trauma Surg 2011;131(1):93-99.

[14] Enneking WF, Dunham W, Gebhardt MC, Malawar M, Pritchard DJ. A system for the functional evaluation of reconstructive procedures after surgical treatment of tumors of the musculoskeletal system. Clin Orthop Relat Res 1993;286:241-246.

[15] Raux S, Abelin-Genevois K, Canterino I, Chotel F, Kohler R. Osteoid osteoma of the proximal femur: treatment by percutaneous bone resection and drilling (PBRD). A report of 44 cases. Orthop Traumatol Surg Res 2014;100:641-645.

[16] Yalcinkaya U, Doganavsargil B, Sezak M, Kececi B, Argin M, Basdemir G, Oztop F. Clinical and morphological characteristics of osteoid osteoma and osteoblastoma: a retrospective single-center analysis of 204 patients. Ann Diagn Pathol 2014;18:319-325. 
[17] Puri A, Agarwal M. Treatment of giant cell tumor of bone: Current concepts. Indian J Orthop 2007;41:101-108.

[18] Moon MS, Kim SS, Moon JL, Kim SS, Moon H. Treating giant cell tumours with curettage, electrocautery, burring, phenol irrigation, and cementation. J Orthop Surg (Hong Kong), 2013;21:209-212.

[19] Lackman RD, Crawford EA, King JJ, Ogilvie CM. Conservative treatment of Campanacci grade III proximal humerus giant cell tumors. Clin Orthop Relat Res 2009;467:1355-1359.

[20] O'Donnell RJ, Springfield DS, Motwani HK, Ready JE, Gebhardt MC, Mankin HJ. Recurrence of giant-cell tumors of the long bones after curettage and packing with cement. J Bone Joint Surg Am 1994;76:1827-1833.

[21] Prosser GH, Baloch KG, Tillman RM, Carter SR, Grimer RJ. Does curettage without adjuvant therapy provide low recurrence rates in giantcell tumors of bone? Clin Orthop Relat Res 2005;435:211-218.

[22] McDaniel S, Goldman GD. Consequences of using escharotic agents as primary treatment for nonmelanoma skin cancer. Arch Dermatol. 2002 Dec;138(12):1593-6.

[23] Osswald SS, Elston DM, Farley MF, Alberti JG, Cordero SC, Kalasinsky VF. Self-treatment of a basal cell carcinoma with "black and yellow salve". J Am Acad Dermatol. 2005 Sep;53(3):509-11.

[24] Rock MG: Curettage of giant-cell tumor of bone: factor influencing local recurrences and metastasis. Chir Organi Mov. 1990, 75 (Suppl. 1): 204-205.

[25] Muheremu A, Niu X. Pulmonary metastasis of giant cell tumor of bones. World J Surg Oncol. 2014 Aug 20;12:261. doi: 10.1186/1477-781912-261.

[26] Benedetti MG, Bonatti E, Malfitano C, Donati D. Comparison of allograft-prosthetic composite reconstruction and modular prosthetic replacement in proximal femur bone tumors: functional assessment by gait analysis in 20 patients. Acta Orthop 2013;84:218-223.

[27] Xu S, Yu X, Xu M, Fu Z. Inactivated autograftprosthesis composite has a role for grade III giant cell tumor of bone around the knee. BMC Musculoskelet Disord 2013;14:319.

[28] Campanacci M, Baldini N, Boriani S, Sudanese A. Giant-cell tumor of bone. J Bone Joint Surg Am 1987;69:106-114.

[29] Anitha N, Sankari SL, Malathi L, Karthick R. Fibrous dysplasia-recent concepts. J Pharm
Bioallied Sci. 2015;7(Suppl 1):S171-2.PMID: 26015701.

[30] Qu N, Yao W, Cui X, Zhang H. Malignant transformation in monostotic fibrous dysplasia: clinical features, imaging features, outcomes in 10 patients, and review. Medicine (Baltimore). 2015;94(3):e369. PMID: 25621678.

[31] Han I, Choi ES, Kim HS. Monostotic fibrous dysplasia of the proximal femur: natural history and predisposing factors for disease progression. Bone Joint J 2014;96-B:673-676.

[32] Tong Z, Zhang W, Jiao N, Wang K, Chen B, Yang T. Surgical treatment of fibrous dysplasia in the proximal femur. Exp Ther Med 2013;5: 1355-1358.

[33] Montalti M, Alberghini M, Ruggieri P. Secondary aneurysmal bone cyst in fibrous dysplasia of the proximal femur. Orthopedics 2009;32:363.

[34] Yazu M, Kin A, Kosaka R, Kinoshita M, Abe M. Efficacy of novel-concept pedicle screw fixation augmented with calcium phosphate cement in the osteoporotic spine. J Orthop Sci 2005; 10:5661.

[35] Bauer TW, Muschler GF. Bone graft materials. An overview of the basic science. Clin Orthop Relat Res 2000;371:10-27.

[36] Long B, Dan L, Jian L, Yunyu H, Shu H, Zhi Y. Evaluation of a novel reconstituted bone xenograft using processed bovine cancellous bone in combination with purified bovine bone morphogenetic protein. Xenotransplantation 2012;19:122-132.

[37] Jeys LM, Suneja R, Chami G, Grimer RJ, Carter $\mathrm{SR}$, Tillman RM. Impending fractures in giant cell tumours of the distal femur: incidence and outcome. Int Orthop 2006;30:135-138.

[38] Mirels H. Metastatic disease in long bones. A proposed scoring system for diagnosing impending pathologic fractures. Clin Orthop Relat Res 1989;249:256-264.

[39] Malizos KN, Zalavras CG, Soucacos PN, Beris AE, Urbaniak JR. Free vascularized fibular grafts for reconstruction of skeletal defects. $\mathrm{J}$ Am Acad Orthop Surg 2004;12:360-369.

[40] Enneking WF, Eady JL, Burchardt H. Autogenous cortical bone grafts in the reconstruction of segmental skeletal defects. J Bone Joint Surg Am 1980;62:1039-1058.

[41] Sun Y, Zhang C, Jin D, Sheng J, Cheng X, Zeng B. Treatment for large skeletal defects by free vascularized fibular graft combined with locking plate. Arch Orthop Trauma Surg 2010;130:473479. 
[42] Hariri A, Mascard E, Atlan F, Germain MA, Heming N, Dubousset JF, Wicart P. Free vascularised fibular graft for reconstruction of defects of the lower limb after resection of tumour. J Bone Joint Surg Br 2010;92:1574 1579.

[43] Arbeitsgemeinschaft Knochentumoren, Becker WT, Dohle J, Bernd L, Braun A, Cserhati M, Enderle A, Hovy L, Matejovsky Z, Szendroi M, Trieb K, Tunn PU. Local recurrence of giant cell tumor of bone after intralesional treatment with and without adjuvant therapy. J Bone Joint Surg Am 2008;90:1060-1067.

[44] Rapp TB, Ward JP, Alaia MJ. Aneurysmal bone cyst. J Am Acad Orthop Surg 2012;20:233-41.

[45] Xing R, Yang J, Kong Q, Tu C, Zhou Y, Duan H. Giant cell tumour of bone in the appendicular skeleton: an analysis of 276 cases. Acta Orthop Belg 2013;79:731-737.

Citation: Gao MX, Li H, Nie DJ, Liu C, Xie WQ, Chang YF, Luo WY, Vascularized Fibular Graft Reconstructing Large Bone Defects after Extended Curettage of Osteolytic Lesions in Lower Extremities. ARC Journal of Clinical Case Reports. 2019; 5(3): 10-20. doi:dx.doi.org/10.20431/2455-9806.0503003.

Copyright: (C) 2019 Authors. This is an open-access article distributed under the terms of the Creative Commons Attribution License, which permits unrestricted use, distribution, and reproduction in any medium, provided the original author and source are credited. 